\title{
KNOWLEDGE AND REASONS FOR BELIEF
}

\author{
Alan Millar \\ University of Stirling
}

\section{The problem}

There are epistemological puzzles that take the form: how can we gain so much from what seems so little? Knowledge from testimony nicely illustrates this. In certain cases, which I shall call straightforward cases, we gain knowledge that something is so from a person's telling us that it is so, despite the fact that we have not, or not obviously, engaged in any reasoning bearing on the credibility of what we have been told. We accept what we have been told straight away on the say so of the informant and thereby gain knowledge. What makes this problematic is that, given the rather special standing we take knowledge to be, it is puzzling how a person's say so, can be the means of acquiring knowledge. Arguably, part of what makes knowledge special is that it implicates justified belief. On the natural assumption that being justified in believing that $\mathrm{p}$ is a matter of having an adequate reason to believe that $\mathrm{p}$, it can easily seem obscure that someone's telling us that $\mathrm{p}$ can ever be an adequate reason to believe that $\mathrm{p}$.

Accepting that there is this difficulty does not commit us to accepting that knowledge admits of a reductive conceptual analysis in terms of justified belief and other conditions. If knowledge does not admit of such an analysis, as has been argued by Timothy Williamson (2000), it still might be that necessarily, one who knows that 
$\mathrm{p}$ is, in a way that is tied up with what it is to know that $\mathrm{p}$, justified in believing that $\mathrm{p}$. This latter view is also disputable. One might reject it on the grounds that while being justified seems to implicate reflective capacities - those involved in thinking about and weighing up reasons — animals that lack such reflective capacities have knowledge. For present purposes I think we can sidestep such matters. I am concerned with human knowledge and thus with the knowledge of agents who have reflective capacities and are capable of thinking about why they believe as they do. I take it as a working assumption that when such agents know that something is so they are, at least normally, justified in believing it to be so on account of having an adequate reason to believe that it is so-a reason to which they will normally have access. I seek to make sense of the idea that, for such agents, knowledge at least normally goes along with being justified in believing.

A quick response to the challenge posed by testimony would be to say that the mere fact that a person tells us that $\mathrm{p}$ never is an adequate reason to believe that $\mathrm{p}$. So it is right that being apprised of this fact is 'too little' to give us knowledge that $p$, but wrong to suppose that this poses a problem. On the contrary, following this line of thought, we can be justified in believing that $\mathrm{p}$ in view of other things we believe which, together with the fact that we have been told that $p$, provide us with adequate reason to believe that $\mathrm{p}$. Non-testimonial cases provide the model. A plausible view with roots in Hume is that, for instance, we can come to know that the grass making up the lawn lacks nutrients on the basis of the fact that it is yellow. We can do so with the help of a generalization to the effect that when grass is yellow it lacks (or is very likely to lack) nutrients. Applied to testimonial cases this suggests that we need a generalization relating to the veracity of the testimonial utterances with which we are confronted. The needed generalization would be to the effect that when somebody of 
a certain sort tells us something and various further conditions are satisfied then what they tell us will be true or very likely to be true. The reason for which we are looking would be constituted by such a generalization along with a corresponding statement to the effect that this speaker is of the relevant sort and the further conditions are satisfied. ${ }^{1}$ An account along these lines would be reductionist in that it assimilates the epistemology of knowledge or justified belief from testimony to a general epistemology of empirical evidence. Attractive though it seems, this approach is not free of difficulties. It is not a trivial matter to specify a generalization covering the informant's utterance on which we could plausibly be taken to rely. It is not that we are powerless to pick out factors that are relevant: type of person, manner of speaking, content of utterance, the immediate context of utterance (the situation in which it is made), the wider context of the utterance incorporating any shared histories of informant and recipient, and the culture or cultures to which they belong. The problem is to work determinate forms of these factors into a generalization that could do the business on a specific occasion. ${ }^{2}$ There are really two problems here. One is that it is far from clear that we routinely have a suitable generalization at our disposal. The other is that it is far from clear that even if we had we would routinely be justified in accepting it when we gain knowledge from testimony. No doubt we shall have had much experience that affects the level of confidence that we have in what we have been told. But it is a further matter whether this experience will have led us even to believe a determinate generalization that will do the job, far less have furnished us with adequate evidence for accepting it.

\footnotetext{
${ }^{1}$ For a recent version, see Fumerton 2006.

${ }^{2}$ Fumerton (2006: 80) works with a schema ('says that $\mathrm{p}$ in conditions $\mathrm{C}$ ') that does not bring out the range of factors and the elusiveness of their determinate forms.
} 
This is the kind of problem I wish to explore in this discussion. In the next section I consider perceptual knowledge. In section 3 I give an indication of how one might develop an account of testimony building on a non-standard account of knowledge from indicator phenomena. An instance of the latter would be knowing that it has rained because the streets and other outside surfaces are wet. From these discussions emerges a conception of the importance of recognitional abilities which in section 4 is developed to yield an account of reasons for belief in the cases under consideration and a general view of the connection between knowledge, justified belief and reasons. Section 5 explores what I call detached standing knowledge. I do not claim to establish my general view on these matters within the space available here, only to have made it plausible enough to merit further investigation.

\section{Perceptual knowledge}

A problem-structure analogous to that described in relation to testimony arises in cases of perceptual knowledge. Here too it can seem that we gain a lot from a little, and it is hard to see how the little can supply us with the required adequate reason. This is how things are liable to seem from a certain theoretical stance that has been widely accepted. On this stance, seeing that Bill has arrived is a matter of being in a certain psychological state- - having an experience such that it looks to one as if Bill has arrived - plus the satisfaction of further conditions. The conditions are, roughly, that Bill has indeed arrived and one's experience is explicable in a way characteristic of normal perception by Bill's having arrived. The question arises as to how the experience can furnish us with a reason to believe that Bill has arrived. The issue concerns how we should think of the reason we have to believe that Bill has arrived in 
the situation in which we see that, and thereby know that, he has. Paradigm cases of believing for a reason are cases in which we believe one thing in view of something else, which we also believe. Thus I might believe that my wife has returned from work in view of the fact that her car is in the driveway. This fact is at least part of my reason for believing that she has returned from work. But, on the face of it, my knowing that Bill has arrived, when I see him arriving, is not a matter of my believing that he has arrived in view of something else that I believe. It simply strikes me on seeing him that he has arrived. I do not appear to believe this because I believe something else that I treat as a reason for me to believe. This creates a pressure to suppose that at some stage we need the idea that experiences themselves can be justifiers. ${ }^{3}$ The idea is not that the fact that one has certain experiences can provide a reason to think that something is so. That would still treat one's justification as provided by propositions one believes. Rather, the point is that one can be justified in believing certain things in virtue of having appropriate experiences, in the absence of any reason not to believe. On this account the experiences themselves are supposed to be justifiers.

It is one thing to feel compelled to accept this view and another to see how it can be true. We would need some account of how experiences can justify beliefs. An apparently promising account is available via a combination of two ideas: (i) that being justified in believing something is to be explained in terms of forming the belief in a competent way_-specifically, in a way that manifests competence in deploying the relevant concepts; (ii) that basing beliefs on experiences of an appropriate type can be a manifestation of conceptual competence, analogous to basing a belief on

\footnotetext{
${ }^{3}$ See, for instance, Pollock 1986 and Pryor 2000. Davidson (1983) objected to any such view. I mounted a defence in Millar 1991.
} 
other things one believes. ${ }^{4}$ Being justified in believing that $\mathrm{p}$ on the basis of other things one believes requires that in forming the belief that $p$ on the basis of those other beliefs one exploits one's mastery of the various concepts involved. Obviously it matters that the other beliefs should have an appropriate standing. (What this must be is debatable.) The analogy for believing that $\mathrm{p}$ when seeing that $\mathrm{p}$ is that the experiences should be of an appropriate sort and that in forming one's belief one exploits one's mastery of concepts implicated by believing that $\mathrm{p}$. This approach has the merit of yielding a way of developing a familiar way of thinking about Dretske's (1970) zebra case and cases like it. Consider a case — the good case—in which I am looking at a zebra in a zoo enclosure, and, in the absence of any countervailing reasons, correctly believe it to be a zebra, and another case - the bad case — in which, in the same setting, I am looking at a mule cleverly disguised as a zebra and, in the absence of any countervailing reasons, incorrectly believe it to be a zebra. On the familiar way of thinking that I have in mind we need to accommodate the idea that these cases are on a par with respect to the justification of the belief. This will seem to be a natural requirement if one accepts the usual understanding of Gettier cases. On that understanding it is assumed that, in cases in which what is believed is concluded from other things one believes, one can be justified even if the other things believed include a falsehood. With respect to perceptual Gettier cases it is assumed that a belief based on misleading experience can be justified. A standard example of the latter is correctly believing that someone one knows is at a certain location in the space in front of one, though one is looking at a life-size photograph obscuring the person one takes oneself to be looking at. An account of justified belief based on conceptual competence, conceived along the lines sketched, gives an explanation of the supposed

\footnotetext{
${ }^{4}$ This is the line I took in Millar 1991.
} 
parity of justification in good/bad pairs: in both cases the belief is competently formed. Looking at the disguised mule I make a mistake in believing it to be a zebra but there is a sense in which it is quite reasonable that I should believe as I do. This reflects the fact that the belief is competently formed, as that is being understood. After all, the animal I am looking at is indistinguishable from a zebra from a point from which I can normally tell that an animal is zebra from the way it looks, and I have not judged carelessly. It is not as if I am under some misapprehension as to what zebras are or what they look like. The mistake is due to the unusual character of the situation. There is then a case for trying to capture the sense in which my belief in the bad case is reasonable in terms of this way of thinking. Its reasonableness reflects the fact the belief is competently formed. This might encourage one to think that the suggested line of thought provides the right account of how experiences can be justifiers. But even if it is granted that there is a sense in which competence is exercised no less in bad cases than in corresponding good cases, there remain problems for the view that experiences can be justifiers.

One obvious problem is that justified belief seems to be a matter of having adequate reasons and experiences seem to be in the wrong category to constitute any kind of reasons. The most natural way to think of reasons is as being constituted by facts or true propositions. (For the purposes of the present discussion I need make no distinction between these.) It is not easy to spell out in general terms what it takes for a truth to constitute an adequate reason to believe something, but we have some sense of what governs our judgements on this matter. We want a truth that constitutes a reason to believe that $\mathrm{p}$ to be something that clinches it that $\mathrm{p}$ or is at least such that it is not likely that the truth should be a truth and it be false that $\mathrm{p}$. There is no similarly natural mode of evaluating beliefs that involves treating experiences as reasons under 
the operative understanding of experiences. Indeed, the operative understanding is a philosopher's construction. Philosophers talk of having a visual experience such that it looks to one just as if Bill has arrived. We can fairly readily acquire an understanding of what this amounts to by coming to understand why it might be thought philosophically illuminating to characterise the experiences in a way that is non-committal with respect to what if anything the subject sees. ${ }^{5}$ The point is to introduce a convenient way of expressing the possibility of more or less radical differences between how it appears to us that things are and how things actually are. But (a) the non-committal conception of experiences does not routinely figure in our thinking about knowledge or beliefs and (b) the order of understanding is from more familiar conceptions of, for instance, seeing $\mathrm{X}$ to a conception of experience as noncommittally characterized. What does figure routinely in our thinking about knowledge and belief are notions of the various modes of perceiving. If we know what it is to have an experience such that it looks as if Bill is arriving, it is in terms of what it is to see Bill arriving. ${ }^{6}$ This should make us wonder whether it is right to work from the non-committal characterizations towards a philosophical account of perception and perceptual knowledge.

A radical response to the foregoing would be to sever the connection between being justified and possessing an adequate reason. ${ }^{7}$ It might be argued that experiences must be justifiers and that there must be some basic a priori principle of justification such that if it perceptually seems to one just as if $p$, then, in the absence

\footnotetext{
${ }^{5}$ The drill described by P. F. Strawson (1979: 43-44) is intended to initiate us into such an understanding.

${ }^{6}$ The point about order of understanding is congenial to those who favour disjunctivist accounts of experience. See Child 1994: 143-46.

${ }^{7}$ James Pryor (2000) treats experiences as justifiers but does not represent them as reasons.
} 
of countervailing reasons, one is justified in believing that $\mathrm{p}$. If there are such principles they are not self-explanatory and, in any case, the problems are not solved by denying that being justified implicates having reasons. There remains the very basic problem that experiences, conceived non-committally, seem to provide too little to account for the special standing in which knowledge consists. The problem might not seem evident. After all, it is routinely accepted that being justified in believing that $\mathrm{p}$ is compatible with its being false that $\mathrm{p} .{ }^{8}$ But even if that is so we still lack an explanation of how perception can settle it that something is so: Gettier-style justification settles nothing. That matters since it is natural to suppose that evidence adequate for knowledge that $\mathrm{p}$ should settle it that $\mathrm{p} .{ }^{9}$ Further, even if it is granted that false beliefs are sometimes justified, and we help ourselves to the account of justification in terms of competence sketched earlier, there remains the problem posed by the fact that our evaluations of beliefs do not routinely deal with the operative understanding of experiences. Here I shall stick with the idea that justified beliefs depends on having reasons, and that reasons are constituted by propositions, and see whether we can end up with a view that reflects our evaluative practices.

\section{Knowledge from indicator phenomena and knowledge through being told}

\footnotetext{
${ }^{8}$ For a contrary view, see Sutton 2007.

${ }^{9}$ I take for granted that when knowledge that $p$ is based on evidence that $p$ the evidence that $p$ must clinch it that $p$ in a sense that entails that there would be this evidence only if $p$. I see this view as being of a type instances of which have been held by Fred Dretske (1971), John McDowell (1982), and Charles Travis (2005). See further my contribution to Pritchard, Millar and Haddock 2010.
} 
As we saw, gaining knowledge from testimony is problematic in straightforward cases in which we accept the testimony straight off on the say so of the informant, because it seems to involve gaining a lot from a little. The issue is how it can supply an adequate reason. In section 1 I outlined a quick response to the problem that involved conceding that the fact that one has been told by someone that $\mathrm{p}$ does not provide an adequate reason for one to believe that $\mathrm{p}$ but which suggests that an adequate reason is available when this fact is combined with a suitable covering generalization. One attraction of this approach is that it applies to testimony what looks like a plausible way of dealing with empirical evidence. By contrast with perceptual knowledge, the problem here is not that what is thought to supply the reason is not of the right category to constitute a reason. It is that the general approach posits reasons that it is far from obvious that we have in the cases under consideration. It is not evident that the needed generalizations are routinely available to us. More specifically, it is not evident that we can so much as specify a determinate generalization that would do the trick; nor is it evident that if there are such generalizations we have adequate evidence for thinking them true.

Against this background it is understandable that some epistemologists dealing with testimony should have been attracted by defaultist conceptions according to which we are justified in accepting what people tell us, and tend to do so, in the absence of reasons to do otherwise. This way of thinking has the merit of doing better justice to the phenomenology — in particular, the straight-off acceptance of what we are told and apparent absence of reliance on supplementary premises to bolster an inference from being told something to the conclusion that what we are told is true. It also makes provision for our being discriminating with respect to believing what we are told. If it is to be made good though it requires a wider picture to make sense of 
why acceptance is the appropriate default stance towards testimony. Wider pictures designed to do this job are available. ${ }^{10}$ I shall not discuss them here but simply record that I am sceptical that any highly general considerations about the social role of testimony or about human rationality will yield an adequate account of how we can gain knowledge from testimony in particular cases. For knowledge that $\mathrm{p}$ from being told that $\mathrm{p}$ in the straightforward cases we need to make sense of the idea that the testimony clinches it that $\mathrm{p}$ and I do not see how a defaultist view can do this. (Recall footnote 10.) A (perhaps) less controversial objection is that it distorts the phenomenology to suppose that in practice, by and large, we trust testimony unless there is reason to do otherwise. When nothing is at stake much of what people tell us washes over us without our adopting any stance towards it. When we do take ourselves to have learned something from being told it, we take the informant to be trustworthy on the matter in hand, not simply in virtue of being an informant in general, whom we have no particular reason to distrust, but as being this informant in this circumstance. The question is what entitles us to do this if we reject the reductionist picture that assimilates the epistemology of testimony to the epistemology of empirical evidence, using the model I described earlier.

The problem with the reductionist picture of testimony is not just that it assimilates the epistemology of testimony to the epistemology of empirical evidence in general. There is reason to think that the implicated account of empirical evidence is itself problematic. It is instructive in the present context to see why this is so.

Of particular interest is what we may call knowledge from indicator phenomena because this provides a model for reductionism about testimony. We gain such

\footnotetext{
${ }^{10}$ See, for instance, Burge 1993. Some of the considerations advanced in Coady 1992 could be adapted to this end. For some critical discussion of such approaches, see Moran 2006.
} 
knowledge when, for instance, we tell from a reading on a thermometer that someone has a temperature of $38^{0}$, or tell from a blood smear on a surface that someone has touched it with blooded hands, or tell from the frost on the grass that it has been freezing overnight. Note that in many cases in which judgements are made from indicator phenomena, the person making the judgement need not be in possession of evidence that directly confirms and establishes a suitable covering generalization. A person trained in the use of a thermometer can tell by applying the technique for its use, and thus know, what temperature a patient has. Such a person is committed to thinking that, for any $\mathrm{n}$, readings of $\mathrm{n}^{0}$ from properly applied thermometers indicate that the patient has a temperature of $n^{0}$. It does not follow that the person need have evidence and on that account know that the generalization is true. Indeed, there are cases in which the relevant generalization might well be false. Imagine a community in which a certain style of house indicates that the resident has some official role in the community, say, that of being a police officer. (If no police officer resides in the house its style is altered.) Suppose that unknown to the people in this community there happen to be other communities in which there are houses in the same style but which are not occupied by police officers. ${ }^{11}$ If I am a member of the community in question I might believe that any house in the given style is occupied by a police officer. If so I would believe falsely, yet by ordinary standards for attributions of knowledge I would not on that account be precluded from being able to tell, and thus come to know, from the style of a house in this community that it is the residence of a police officer. ${ }^{12}$ Examples such as this, when taken along with the problem already

\footnotetext{
${ }^{11}$ The example is of the familiar fake-barn type (Goldman 1976, and much discussed subsequently).

${ }^{12}$ While the domain of quantification of universal generalizations is often determined in part by contextual factors, I can see no reason to assume that the members of the envisaged
} 
mentioned of identifying suitable covering generalizations for indicator cases for which we have adequate evidential support, strongly suggest that acquiring knowledge from indicators has more do to with mastering a technique than it has to do with having adequate evidence for covering generalizations.

The conclusion just reached can be reinforced by reflecting on how we identify a phenomenon as having some indicative significance. Think of something as straightforward as telling from the wetness of surfaces outdoors (streets, pavements, etc.) that it has been raining. This is a simple ability yet it requires one to discriminate between rain-indicating wetness and wetness that has different causes, like people washing their cars, street cleaning vehicles, hydrants spraying water, and so forth. Learning to do this is a matter of learning to recognize rain-indicating wetness. The kind of procedure here is not in any fundamental way different from the procedure in perceptual cases, like learning to recognize goldfinches or thermometers by sight. It is a matter of being attuned to just the right kinds of visual appearance. It is not a matter of acquiring a list of features that collectively are distinctive, learning to judge when they are present, and on particular occasions basing a judgement that the thing in question is a goldfinch, or whatever. Indeed, one might have the recognitional ability yet lack the conceptual resources to form judgements to the effect that such-and-such a feature is present. Of course, in judging something by sight to be of some kind one is responding to its features, but the response is a recognitional response to the distinctive Gestalt that the features make up, not an inferential response to considerations pertaining to the features. The same applies to indicator cases. One learns that the right kind of wetness indicates that it has rained. The ability thus

community would not understand the generalization in question as being true with respect to dwellings in general rather than simply to the dwellings in area with which they are familiar. 
acquired deserves to be regarded as recognitional. It is a matter of being able to recognize that occurrences of an observed phenomenon — wetness of the right kindhave a certain significance: they indicate that it has rained. The work of learning is towards making the right kind of discriminations. It would not be false that one has this ability if there happened to be some place where, because of the peculiar waterspraying practices of the inhabitants, you could not tell that it has rained recently from the wetness of the surfaces in view. If there were such a place it could be false that when (or even most times when) there is the wetness that we associate with rain it has rained. Yet this would be compatible with our being able, around here, to tell that it has rained by exercising the ability.

It is of some interest to note in passing that the abilities of which I am speaking amount to a kind of competence in the deployment of concepts. But competence so understood is very different from that discussed in section 2 in connection with the supposed parity of justification in pairs of good and bad cases. It is built into perceptual-recognitional abilities that they are abilities with respect to favourable environments and that their exercise is the acquisition of knowledge. In a suitably strange environment I might not be able to recognize something to be a zebra from the way it looks, because too easily could something look that way and not be a zebra. The nature of the environment is crucial for whether one has the ability to recognize things in that environment to be of some kind. ${ }^{13}$

Our reflections on indicator cases support the view that the standard way of thinking about indicator cases is inadequate. I have suggested that knowledge from

\footnotetext{
${ }^{13}$ There are theories (e.g., that of Ernest Sosa (2007)) on which a subject is represented as having a true belief that is competently formed when luckily looking at a barn. The understanding of competence is not the same as any understanding on which the relevant competences are recognitional abilities. I explore the difference in Millar 2009.
} 
indicator phenomena is best understood as a kind of recognitional knowledge made possible by suitable recognitional abilities. As I have already observed some such abilities are exercised in the acquisition of perceptual knowledge. ${ }^{14}$ If I can tell whether a bird is a goldfinch from the way it looks, and I exercise that ability when looking at a goldfinch, I thereby acquire knowledge that a goldfinch is there. The knowledge is recognitional rather than being a matter of drawing a conclusion from other things I believe. I have sought to make it plausible that recognitional abilities are also exercised in recognizing occurrences of a phenomenon as having a certain indicative significance. In these cases the state of affairs indicated need not fall within the scope of what we currently perceive. In telling that it has been raining from the wetness that is around I need not see the rain; in telling that a patient has a temperature of $38^{0} \mathrm{I}$ do not see the temperature. It is striking though that in many of these indicator cases the natural description of the observed phenomenon entails that it has the significance in question. Tracks on a path, recognized as deer tracks, are naturally described as, of course, deer tracks, entailing that they have been caused by the passage of deer. That marks on a road are skid marks entails that they have been caused by a skidding vehicle. The fact that these descriptions entail something about the cause of the phenomenon described is not at odds with the recognitional character of the knowledge that a suitably equipped person can acquire by discerning the phenomenon. Whether or not our natural way of describing the indicator phenomenon entails anything about what it indicates, it is very often, perhaps always, natural to talk in perceptual terms of our knowledge of what is indicated. ${ }^{15}$

\footnotetext{
${ }^{14}$ See further Millar 2007, 2008a, 2008b, 2009, and my contribution to Pritchard, Millar and Haddock 2010.

${ }^{15}$ This is how Dretske (1969) conceives of such cases.
} 
The role of recognition is of first importance in connection with an overarching theme of this essay, which concerns the problem posed by kinds of knowledge with respect to which it seems puzzling that we gain so much from what apparently is so little. It contributes towards appreciating that in the problem cases we have more to go on that might initially appear. More specifically, (a) in virtue of our recognitional abilities we can take in facts that are rich in the sense that they concern not just superficial features of objects or situations, and (b) in exercising recognitional abilities whereby we take in rich facts we are responsive to phenomena that have a high degree of informational richness. A good example of both of these points is the recognition of people. We can recognize some people as named individuals. I can see that it's Bill, a person I know, entering the room, not just something with certain superficial features. In doing so I am responsive to a host of features that make up the visual appearance of Bill entering. While I tell that it's Bill from his visual appearance I could not give a specific description of everything that goes to make up that appearance. In this kind of case we respond to a Gestalt that is informationally rich, being the resultant of determinate forms of a number of dimensions of variation. The lesson to draw, as much from indicator cases as from perceptual cases like that just described, is that after all we have a lot to go on. The real puzzle is not that we gain a lot from a little, since there is a great deal to which we respond when we gain knowledge of the kinds under discussion. The problem is to make sense of how the many features to which we respond, can impinge on our thinking. It is in connection with this that it matters that we acknowledge the role of recognition and recognitional abilities. We court failure if we try to do justice to the relevance of the features by supposing that we register their presence at the level of judgement and then apply a suitable covering generalization. The problem for that view is not just whether 
routinely we have evidence for the required generalization, nor even that some of the generalizations in play in the cases in question might be false (as suggested by analogues of fake barn cases). It is that in practice we need not take in the relevant features at the level of judgement. To recognize people, animals, birds, plants, or, for that matter, smoke, skid marks, deer tracks, and so forth you need to 'get your eye in'.

Analogous considerations apply to the epistemology of testimony. For gaining knowledge from testimony in straightforward cases it matters that the informant is trustworthy with respect to the thing told and that the recipient of the testimony has identified the informant as one who may be trusted on that matter. The reductionist approach can be viewed as aiming to explain how recipients identify trustworthiness in terms of features of the occasion of utterance that make it such that utterances with those features are always, or highly likely to be, true. That a host of such features is relevant to the case is not in dispute. If we reject the reductionist approach then we need to account for how they bear on our thinking and make sense of how the recipient can end up with knowledge. On the approach that I commend, instead of supposing that we register the features at the level of judgement, we should think rather in terms of our having acquired a certain sensibility that enables us to pick out acts of telling that may be relied upon. ${ }^{16}$ I envisage this sensibility as being shaped by our experience of individual people and of the workings of the human world and our physical environment. The shaping is to be conceived as a matter of honing our discriminative capacities rather than as supplying us with information on the basis of which we accept generalizations that we then apply to particular cases. It is not that acquiring new information is irrelevant. Suppose that I have learned visually to

\footnotetext{
${ }^{16}$ Miranda Fricker (2003) deploys the notion of a testimonial sensibility in the context of a discussion of cases in which reliable informants are not taken seriously by others.
} 
identify roses from examples, or illustrations of examples of garden-variety roses. When walking by a hedgerow along a country road I fail to recognize a rambling rose as a rose. When it is pointed out to me that this rambling plant is a rose, though its flowers seem so unlike the full blooms of garden roses, I acquire new information about how roses can look. My ability to tell by sight when a flower is a rose is refined so that I avoid false denials that I would have made previously and become generally more circumspect about denying that something is a rose when it is unlike the flowers I originally learned to call roses. It might well be that all this is accompanied by some adjustment to rough generalizations I have previously accepted. But it is the refinement of the recognitional ability that is explanatorily central. Any generalizations that informed my thinking about roses would be unspecific with respect to features. I thought of roses as having full blooms like these (pointing, say, to examples in a garden flowerbed). I then realise that roses can look like the rambling roses one sometimes finds in country hedgerows, so I no longer think that roses always have the flowers of the typical garden varieties. Closely analogous considerations apply to straightforward cases of testimony. The features of an act of telling that lead us, rightly, to accept what we are told are elusive. In particular circumstances people come over to us as telling the truth or as not telling the truth or leave us in doubt or indifferent as to whether they are telling the truth. As I remarked previously, we are not at a loss to point to some of the variable factors that influence our response. It is implausible to suppose that we latch on to determinate forms of these at the level of judgement, but entirely realistic to suppose that discriminative capacities come into play, capacities that not only explain our responses to what we are told but which can amount to abilities to tell that the informant is telling the truth. If the Departmental secretary phones me at home to tell me that a student urgently 
wishes to see me, I thereby know that there is a student who urgently wishes to see me. That requires both that the secretary should be highly reliable on such matters and that I am attuned to this and to the character of her communication. My point has been that this attunement is better seen as involving a sensibility acquired through experience than explained in terms of the reductionist model of reasoning from matters of fact.

I have only gestured towards an account that accords a central role to sensibility in the epistemology of testimony. A fuller account should, I believe, accord an equally central role to the idea that there is a social practice surrounding the speech act of telling. I mean by this that telling is a move in a cluster of essentially rule-governed activities into which we are socially initiated. The practice accounts for the ease with which we can identify utterances as acts of telling whereby speakers give others to understand that they are informing and thus speaking from knowledge. ${ }^{17}$ It also accounts for widely shared understanding that telling is supposed to impart knowledge. I do not, however, think that an adequate account of the epistemology testimony drops out of the theory of the speech act of telling any more than an account of what justifies us in trusting promises made to us falls out of the theory of the speech act of promising. In both cases the rules of the practice can be readily flouted. We need in addition an account of the powers of discrimination whereby we can, sometimes, trust the informant or the person making the promise.

\footnotetext{
${ }^{17}$ The operative conception of a practice is outlined in Millar 2004 and applied to testimony in Millar 2010 and in my contribution to Pritchard, Millar and Haddock 2010. I take for granted that not every act that counts as an assertion is an act of telling. One can assert things in giving advice, or expressing opinions, for instance, without being in the business of telling and thus giving it to be understood that one is informing.
} 
Even if what I have said thus far about perceptual knowledge, knowledge from indicators, and knowledge from testimony seems promising it has probably not escaped notice that I have not as yet explained how reasons fit into the picture. It is to this that I now turn.

\section{Knowing and having reasons to believe}

I see my neighbour in her garden and thereby come to know that she is in her garden. By the operative assumptions I am justified in believing this since I have an adequate reason to believe it. Common sense says that my reason is that I see her in her garden, or something along these lines. Of course, it could be true of me that I see her but do not know that it is she. I need to recognize the person I am looking at as my neighbour. In other words, I need to see that it is she. Strictly, it is the fact that I see that she is in her garden that is my reason for believing that she is there. All this is unexceptionable from the perspective of common sense, but it can all too easily seem unsatisfying to the epistemologist. Though there are notable exceptions, epistemologists have not in general given factive states, like seeing that something is so, a central role in their accounts of the justification that is linked with our perceptual knowledge. ${ }^{18}$ It is not difficult to see why. The reason I am supposed to have in the case in question is that I see that my neighbour is in her garden. Call the proposition that constitutes this reason $\mathrm{R}$. It seems that if $\mathrm{R}$ is to be available to me to serve as a reason to believe that my neighbour is in her garden then I must have reason to believe it. But now the worry is that since $\mathrm{R}$ is true only if my neighbour is in her

\footnotetext{
${ }^{18}$ Notable exceptions include McDowell 1994, Williamson 1995 and 2000, Stroud 2004, and Cassam 2007.
} 
garden it looks as if I shall need to have reason to think that she is in her garden, if I am to have reason to think that I see that she is in her garden. But we were assuming that the former reason - the reason to believe that she is in her garden-was constituted by R. So it looks as if our account gets us nowhere. In explaining why I have a reason to believe that my neighbour is in her garden I have invoked a reason, constituted by $\mathrm{R}$, which it seems would be available to me only if I have a reason to believe that my neighbour is in her garden - a reason that, on pain of circularity, cannot be given by $\mathrm{R}$. And if I have some other reason to believe that my neighbour is in her garden then the original proposal is at best incomplete. Before diagnosing what goes wrong with this line of thought I shall say how, in my view, we should think of the situation.

First, we need to note that I recognize my neighbour because I have a specific recognitional ability that serves this purpose - in suitable conditions I am able to tell by looking at a person whether or not he or she is my neighbour. On this occasion I have exercised this ability and have thereby come to know that my neighbour is in her garden. There is no doubt that the natural way to spell out my reason for taking my neighbour to be there is in terms of the fact that I see that she is there. So next we need to explain how that reason is available to me- how I know that I see that she is there. This is not so very difficult. For my knowledge here is also recognitional, arising as it does in direct response to my current visual experience, via the exercise of a certain recognitional ability, specifically, an ability to tell by looking at an F/something G/X that I see it to be an F/something G/X. In the case in hand, I recognize my neighbour to be someone I see to be my neighbour in her garden. That amounts to knowing that I see that she is in her garden. It would be at least misleading to say that I introspect my experience for my attention is directed outwards towards 
my neighbour. Just as I exercise a recognitional ability when I apply the concept of my neighbour being in her garden to my neighbour, in direct response to the visual experiences I have as I look over at her in the garden, so I exercise a distinct recognitional ability when I apply the concept seeing my neighbour to be in her garden to me and my neighbour,respectively, in direct response to the very same experiences. By exercising these abilities I know both that my neighbour is in her garden and that I see that she is. The fact made available to me by knowing that I see that she is there serves as a reason to believe that she is, and for some time thereafter serves as a reason to believe that she was then in her garden.

A significant feature of this account is that we explain how I know that my neighbour is in her garden without adverting to the reason for me to believe that she is that is constituted by the fact that I see that she is there. Rather than account for the knowledge in question in terms of believing for a reason, we account for my possession of a reason for believing in terms of my possession of two items of knowledge-first-order knowledge that she is there, and second-order knowledge that I see that she is there-along with my understanding of the relevance of my seeing that she is there to whether she is there. The second-order knowledge is my access to a reason to believe what $\mathrm{I}$ know in the first-order way. The problem noted in the paragraph before last was how to account for the availability to me of the reason to believe that my neighbour is in her garden that is constituted by the fact that I see that she is. It seemed that this fact would be available to me only if I have reason to believe that my neighbour is in her garden. Ex hypothesi the reason for so believing is constituted by the fact that I see that my neighbour is in her garden, which takes us nowhere in explaining how the fact in question is available to me. Under the present account we explain the availability of this fact in terms of the exercise of a second- 
order recognitional ability that works in tandem with the first-order recognitional ability whereby I come to know that my neighbour is in her garden. The problem is thus avoided. The reason we are looking for is what pre-theoretically we all know it to be: I see that my neighbour is in her garden. Of course, if I were trying to give a reductive conceptual-analytical account of what it is to know that my neighbour is in her garden, this account would be hopeless, since the very idea of a recognitional ability implicates the concept of knowledge. But the account is still informative since I might have come to know that my neighbour is in her garden by some other means than through seeing her and recognizing her.

The account reverses the traditional philosophical order of explanation as between knowledge and justification in cases of perceptual knowledge. Possession of justification in these cases arises out of what we know about our environment and about our mode of perceptual access to it. This removes any incentive to address the problem of justification for perceptual knowledge by looking for justification in experiences, conceived in non-committal terms, yet it accords perception an explanatory role in relation both to the acquisition of knowledge and the possession of reasons. Provided that we have suitable recognitional abilities, it is what we perceive that enables us both to know that something is so through perceiving that it is so and to have access to a reason to believe that it is so.

In indicator cases the natural explanation of how we come to know is that we have discerned, often directly through perception, that the indicator phenomenon has occurred, and are able to recognize the significance of the occurrence of that phenomenon. Recognizing the significance of the wetness of surfaces outside just is seeing that this wetness indicates, and thus provides a clinching reason to think, that it has been raining. The same applies to straightforward testimonial cases. Someone's 
telling me that $\mathrm{p}$ can be a reason to think that $\mathrm{p}$, and as in other indicator cases, it can be a reason to think that $\mathrm{p}$ that clinches it that $\mathrm{p}$. But one has to be suitably equipped to recognize this reason for what it is.

Earlier I challenged the idea that we can explain knowledge from indicator phenomena in terms of having justification deriving from evidence for believing a suitable covering generalization. The challenge leaves me with a challenge in turn. Consider the case of telling that a vehicle has skidded from marks on the road. If I do this, I do not do it blindly. That is to say, I do not simply find myself judging that a vehicle has skidded with no understanding of what led me so to judge. I am aware that I have judged that a car has skidded on the basis of the presence of the marks and it is part of my understanding of what must have happened, and of my ability to tell what must have happened, that marks of this sort indicate that a vehicle has skidded. So it is natural to ask what entitles me to suppose that this is so. The right answer might simply be (i) that, at least in the environment in which I make judgements to the effect that a vehicle has skidded on the basis of such marks, such marks always or very nearly always do indicate that a vehicle has skidded, and (ii) that I have learned that marks of this sort indicate that a vehicle has skidded. What I have thus learned is a generalization but we need to recall the discussion about generalizations in section 2 . I need not have adequate direct evidence is support of the generalization. Much of what we learn is learned from others; I need not have exercised the discriminative capacities required to gain knowledge through testimony any more than very young children at school, who imbibe information from teachers, need have exercised such discriminative capacities. (I shall say more about this in section 5.) I might simply have learned a technique — that this is a way of telling that a vehicle has skidded — and 
as part of that learning I have acquired an understanding that there is this technique and that I have it.

It is against this background that I wish to account for the acquisition of knowledge through testimony. We need, I think, to turn our attention away from covering generalizations and towards the sensibilities that enable us to discriminate truthful acts of telling. These sensibilities are applied not simply to discriminate between people, but to pick out from among a person's utterances those that are to be believed on the say so of that person. People who are knowledgeable on some topics are not on others. Those who are sincere on some topics can be insincere on others. It is only through experience that we become attuned to picking out what is to be believed. However, the role of experience is not best conceived as that of supplying evidence on the basis of which we hold people trustworthy on this or that topic. Its role is that of inculcating and shaping a sensibility.

\section{Detached standing knowledge}

There is a type of knowledge that has not been extensively discussed though much of our knowledge is of this type. It is knowledge of factual matters that we have picked up and retained though we have lost touch with the relevant sources of information. I call it detached standing knowledge. This is of interest both because it poses further problems about reasons for belief and because reflection on this type of knowledge will serve to reinforce the claim that the epistemological role of experience is not confined to that of supplying evidence on which we base our beliefs. I suspect that the reason why detached standing knowledge has not received much discussion is that it is assumed that it is straightforwardly based on evidence. The matter is more complicated than this suggests. 
I know that kangaroos are marsupials. I have learned this from numerous sources of information including books and documentary films, but I do not recall any specific source. Is my current knowledge evidence-based? One might say that knowledge based on evidence is simply knowledge that was acquired through encounters with evidence and that has been retained. In that rather weak sense this knowledge would be knowledge based on evidence. Yet the fact that the evidence explains how I came to acquire the knowledge does not account for the status of my knowledge now. For one thing, I have lost touch with the evidence: no memory of it is playing any role in sustaining my current knowledge. For another, my past encounters with the relevant sources of information do not explain why I count as having retained the knowledge rather than just a willingness to avow that I know.

We can, I think, make sense of the idea that we routinely have knowledge based on evidence in a stronger sense. I might know that deer were in the vicinity yesterday because I recall seeing fresh deer tracks. In that case the manner in which I now know that there were deer around yesterday is tied to recollection of the evidence provided by the tracks. It is based on the evidence recalled, not just in that my having seen the tracks caused me to know in the first place but in the sense that the recalled evidence plays a role in both sustaining my knowledge and explaining why I now know. My current knowledge that kangaroos are marsupials is not like that: it is not evidencebased in that strong sense. Even if it is evidence-based in the weaker sense, we still need an explanation of why it maintains its status as knowledge. I want to sketch a picture of detached standing knowledge that makes abilities central once again.

The key idea is that detached standing knowledge is, roughly speaking, an ability to recall a fact. For convenience I shall take recall to include cases like that in which, faced with the question, 'What is the capital of $\mathrm{X}$ ?' one can correctly answer, ' $\mathrm{Y}$ ' as 
well as cases in which, faced with the question 'Is $\mathrm{Y}$ the capital of $\mathrm{X}$ ' one can correctly answer 'Yes'. One might be able to recall that $\mathrm{Y}$ is the capital of $\mathrm{X}$ in the second way, yet not be able to recall it in the first way. The abilities in which our detached standing knowledge consists have been acquired either through direct confrontations with the relevant facts or through reliable sources of information that record or report the relevant facts. Some of our knowledge was originally inculcated by teachers. We soaked up the facts, quite reasonably trusting our teachers. We might have learned some geographical facts through news reports of areas of conflict, again quite reasonably trusting the sources on such matters. But we should not think of what is happening here on the model of gaining knowledge from testimony if only because much of what we have imbibed has not brought into play the discriminatory capacities that are necessary for the acquisition of knowledge on the say so of another. On the model I suggest, we acquire the ability to recollect a fact through encounters-usually repeated encounters - with reliable sources of information. The role of experience is that of honing the ability rather than furnishing us with evidence-based knowledge in the sense explained above - the strong sense that requires that recollection of the evidence plays a role in sustaining the knowledge. It is important not to take the view to imply that any disposition to acknowledge that it is a fact that such-and-such counts as knowledge of that fact. It matters that the facts recalled are available, and became available to us, though reliable sources.

A strength of the proposed account is that it accommodates the possibility that much of our standing knowledge derives from having soaked up information before we had the discriminatory capacities for weighing up testimony and other sources of information, which is to say, before we were in a position to acquire evidenced-based knowledge. Indeed, since this seems to be a very live possibility, a weakness of the 
view that all standing knowledge is evidence-based is that it can account for early learning only by finessing on what it takes to have evidence-based knowledge. There is no need to go in for such finessing if we acknowledge that experience can have an ability-inculcating role that is distinct from its role in providing us with evidence.

Adopting this view, can we respect the idea that, even with respect to detached standing knowledge, reflective agents routinely know how they know? The first point to note is that we can discriminate between, on the one hand, what we know, clearly recalling it to be so, and, on the other hand, what we think might well be so but do not know. If we are sufficiently discriminating in these matters, our confidence that we recall some fact can be an indicator that what is recalled is a fact - an indicator from which we tell that it is a fact. These discriminatory capacities are possessed and exercised in the context of an understanding of the workings and practices of the human world and of our own experience of sources of information. If we do not know specifically how we came to know the facts in question, we know about the kind of sources from which we gleaned our information and we know that we make use of these sources. The upshot is that we can rightly be confident that we remember some fact if we have exercised a capacity for discriminating between what we do and do not remember. Such a capacity will be informed by an understanding of the general ways in which the information would have been acquired. In these cases we do not know specifically how we came to know, but there is a sense in which we still know how we now know. We know in that we remember.

How can detached standing knowledge that $\mathrm{p}$, as I have conceived it, yield justified belief that $\mathrm{p}$ ? My reason for thinking that kangaroos are marsupials is simply that I remember that kangaroos are marsupials. Ask me if Tasmanian Devils are marsupials and I could not say without checking. But that kangaroos are marsupials I 
know because I remember and the fact that I remember can serve as a reason for believing this to be so. So long as I remember, and am good at telling what I remember, this knowledge and this justification will be sustained.

\section{Conclusion}

The perspective I have outlined explains how with respect to various kinds of knowledge we gain a lot from what initially seemed to be so little. It strengthens the case for thinking that we gain fresh insights into how best to make sense of various kinds of knowledge if we think of knowledge as prior in the order of explanation to being justified. The task for a substantive epistemology is to account of how we acquire knowledge of the various kinds, why what we acquire counts as knowledge, and how the knowledge can yield justified belief. I have addressed these matters by according a central role to recognitional abilities in relation to perceptual knowledge, and knowledge from indicators. I have given some indication of the direction that an account of knowledge from testimony should take. In relation to these kinds of knowledge I have linked the availability of a reason for belief to an understanding of how we know what we know. Finally, I explored a way of dealing with detached standing knowledge and the related problems that it poses. Much more needs to be investigated but I hope to have conveyed that enquiry in this direction is worthwhile. $^{19}$

\footnotetext{
${ }^{19}$ The ideas outlined in this paper derive from work on a project on the Value of Knowledge funded by the UK's Arts and Humanities Research Council. I am grateful to the Council for its support and to my fellow participants, Adrian Haddock and Duncan Pritchard, for numerous helpful discussions. Special thanks are due to Adrian and to an anonymous reader for written comments that I believe led to improvements.
} 


\section{REFERENCES}

Burge, T. (1993) 'Content Preservation', The Philosophical Review, 102, 457-88.

Cassam, Q. (2007) 'Ways of Knowing', Proceedings of the Aristotelian Society, New Series, 107, 339-58.

Child, W. (1994) Causality, Interpretation and the Mind (Oxford: Clarendon Press).

Coady, C. A. J. (1992) Testimony: A Philosophical Study (Oxford: Clarendon Press).

Davidson, D. (1983) 'A Coherence Theory of Truth and Knowledge' in D. Henrich (ed.) Kant oder Hegel. Stuttgart: Klett-Cotta. Reprinted in E. LePore (ed.) Truth and Interpretation: Perspectives on the Philosophy of Donald Davidson (Oxford: Blackwell, 1989), 307-19 and in Davidson's collection Subjective, Intersubjective, Objective (Oxford: Clarendon Press, 2001), 137-53.

Dretske, F. (1969) Seeing and Knowing (London: Routledge and Kegan Paul).

Dretske, F. (1970) 'Epistemic Operators’ The Journal of Philosophy, 67, 1007-1023. Reprinted in Dretske 2000, 30-47.

Dretske, F. (1971) 'Conclusive Reasons’ Australasian Journal of Philosophy, 49, 122. Reprinted in Dretske 2000, 3-29.

Dretske, F. (2000). Perception, Knowledge and Belief; Selected Essays. Cambridge: Cambridge University Press. 
Fricker, M. (2003). 'Epistemic Justice and a Role for Virtue in the Politics of Knowing', Metaphilosophy, 34, 154-73.

Fumerton, R. (2006) 'The Epistemic Role of Testimony: Internalist and Externalist Perspectives' in Lackey and Sosa 2006, 77-92.

Goldman, A. (1976) 'Discrimination and Perceptual Knowledge' The Journal of Philosophy, 73, 771-91.

Lackey, J, and Sosa, E. (eds.) (2006) The Epistemology of Testimony (Oxford: Clarendon Press), 77-92.

McDowell, J. (1982). 'Criteria, Defeasibility, and Knowledge', Proceedings of the British Academy, 68, 455-79. Reprinted in McDowell 1998.

McDowell, J. (1994) 'Knowledge By Hearsay’ in B. K. Matilal, and A. Chakrabarti, (eds.) Knowing from Words: Western and Indian Philosophical Analyses of Understanding and Testimony (Kluwer: Dordrecht), 195-224. Reprinted in McDowell (1998).

McDowell, J. (1998) Meaning, Knowledge, and Reality (Cambridge, MA.: Harvard University Press, 1998).

Millar, A. (1991) Reasons and Experience (Oxford: Clarendon Press).

Millar, A. (2007) 'What the Disjunctivist is Right About', Philosophy and Phenomenological Research, 74, 176-98.

Millar, A. (2008a). 'Perceptual-Recognitional Abilities and Perceptual Knowledge' in A. Haddock and F. E. Macpherson (eds.) Disjunctivism: Perception, Action, Knowledge (Oxford: Clarendon Press), 330-47.

Millar, A. (2008b). 'Disjunctivism and Skepticism' in J. Greco (ed.) The Oxford Handbook of Skepticism (New York: Oxford University Press). 
Millar, A. (2009) 'What is it that Cognitive Abilities are Abilities to Do', Acta Analytica, 24, 223-36.

Millar, A. (2010). 'Knowing From Being Told' in A. Haddock, A. Millar and D. Pritchard (eds.) Social Epistemology (Oxford: Oxford University Press).

Moran, R. (2006). 'Getting Told and Being Believed' in Lackey and Sosa (2006), 272-306,

Pollock, J. (1986). Contemporary Theories of Knowledge. (Lanham, MD.: Rowman and Littlefield).

Pritchard, D., Millar, A., and Haddock, A. (2010) The Nature and Value of Knowledge: Three Investigations (Oxford: Oxford University Press).

Pryor, J. (2000). 'The Skeptic and the Dogmatist', Noûs, 34, 517-49.

Sosa, E. (2007) A Virtue Epistemology: Apt Belief and Reflective Knowledge. (Oxford: Clarendon Press).

Strawson, P. F. (1979). 'Perception and Its Objects' in G. F. Macdonald (ed.) Perception and Identity: Essays presented to A. J. Ayer with his replies to them, (London: Macmillan), pp. 41-60.

Stroud, B. (2004). 'Perceptual Knowledge and Epistemological Satisfaction' in J. Greco (ed.) Ernest Sosa and His Critics (Oxford: Blackwell), 164-73.

Sutton, J. (2007). Without Justification. (Cambridge, MA.: MIT Press).

Travis, C. (2005) ‘A Sense of Occasion', The Philosophical Quarterly, 55, 286-314. Williamson, T. (1995) 'Is Knowledge a State of Mind?', Mind 104, 533-65.

Williamson, T. (2000) Knowledge and Its Limits (Oxford: Oxford University Press). 300610 